\title{
El nacionalismo latinoamericano en los umbrales del siglo XXI
}

La independencia de España y Portugal dejó a las sociedades latinoamericanas el desafío de constituirse como sociedades nacionales. La exclusión y el elitismo que siguieron inmediatamente después del movimiento independencista no dieron pie para la fundación de esa comunidad imaginada e imaginaria que es la nación. $Y$ es que si bien los esfuerzos para construir la nación —esfuerzos que encontraron su mejor expresión en el plano de la creación ideológico-cultural- son inseparables del proceso de formación de los estados nacionales, así como de las guerras de independencia de principios del siglo XIX, es indudable que dicho proceso tuvo un carácter excluyente, ya que en esencia se trató más de un conflicto que opuso a criollos y peninsulares que de la incorporación de los vastos conglomerados sociales indígenas y populares a un proyecto nacional $(\mathrm{F}$. Zapata, F., Ideología y política en América Latina. México, 1990).

Ei reto de construir la nación, como un proyecto nacional incluyente e integrador, es asumido por José Martí (1863-1895), en quien la filiación nacionalista encuentra no sólo una de sus formulaciones teóricas más elaboradas, sino un compromiso político radical y, por ello, ejemplar, para las futuras generaciones de nacionalistas latinoamericanos. En José Martí, la construcción de un proyecto nacional para Cuba suponía "(1) la necesidad de ganar una patria independiente...; (2) la posibilidad de vencer al colonialismo español deteriorado dentro y fuera de Cuba; (3) la imperativa simultaneidad de una batalla contra el imperialismo norteamericano naciente y amenazador; y (4) la creación de instituciones democráticas con un significativo carácter popular e igualitario" (J. Le Riverend, "Cuba: del semicolonialismo al socialismo" (1933-1975)", p. 44. En P. González Casonova (Coord.), América Latina: historia de medio siglo. 2-México, Centroamérica y el Caribe. México, 1990). Para el prócer cubano, la construcción de la nación requiere de una alianza política que, integrando a los diferentes sectores de la sociedad, permita la reivindicación de lo propio, es decir, "lo que quede de aldea en América". Y ello supone juntar lo diverso, recurriendo a la propia tradición para constituir un nacionalismo latinoamericano, rechazando modelos sociales ajenos a la realidad del continente.

Ahora bien, para José Martí, la reivindicación de lo propio, de lo autóctono y genuino, tiene una finalidad política específica: oponerse a la dominación colonialista e imperialista. Es así como el nacionalismo se convierte, para Martí, en un nacionalismo revolucionario. "De aquí nace la concepción antiimperialista que afirma a la nación frente al expansionismo y no se limita a defender una formal independencia política sino también a propiciar un desarrollo económico auténticamente nacional" (F. Zapata, Ibid. p. 39). La nación y su desarrollo sólo son posibles frente a ese otro que es el imperialismo, cuya dinámica y expansión son 
contrarias por naturaleza a la constitución de la nación. La identidad nacional se construye, así, en un proceso en el que diversos sectores sociales clase media, campesinos, obreros e indígenas-, aglutinados en un amplia alianza política - expresión de la integración social de la nación-, se movilizan contra el imperialismo y sus aliados internos, cuya finalidad es la destrucción de la "aldea", es decir, la depredación de los recursos naturales y el desprecio a las tradiciones autóctonas en nombre de la civilización.

Con José Martí, pues, nace el nacionalismo revolucionario en América Latina. A principios del siglo XX, la izquierda naciente en el continente especialmente por obra de Luis Emilio Recabarren (1876-1924) y Julio Antonio Mella (1903-1929) asume la propuesta nacionalista revolucionaria martiana, pero con una modificación importante: si para Martí la revolución era, ante todo, un cambio moral, para Recabarren y Mella "es un proceso que depende de la voluntad de los hombres" (F. Zapata, Ibid., p. 59). Concreción de esta voluntad revolucionaria es la organización de la clase obrera, es decir, la fundación de los partidos comunistas, que encuentran en Recabarren y Mella a dos de sus primeros conductores. Y es así -con el trabajo de estos dos revolucionarios - como el nacionalismo se inserta en el proyecto socialista latinoamericano, con el cual convivirá a lo largo del siglo XX. Más aún, a partir de este momento, la construcción de la nación será un bandera asumida de pleno derecho por los socialistas latinoamericanos.

Si para el nacionalismo revolucionario de cuño martiano la nación - como hemos visto- se construye en oposición al imperialismo, así como a los que al interior de ella lo promueven, para el naciente socialismo del continente esa oposición tiene que ser una oposición organizada e inspirada en la doctrina socialista de Marx, Engels y Lenin. $\mathrm{Y}$, como no puede ser de otro modo, debe tratarse de una oposición revolucionaria y antiimperialista, ya que la nación sólo puede ser construida por obra de una revolución que se enfrente a la dominación interna y externa. Revolución, socialismo anti-imperialismo y nación: he aquí los cuatro elementos indisolubles del proyecto nacionalista de la izquierda socialista latinoamericana de principios de siglo.

Esos tres elementos han coexistido en el proyecto socialista a lo largo del siglo $\mathrm{XX}$, aunque los mismos sufrieron el efecto negativo de la "oficialización comunista" que se impuso a partir de la década de los treinta en prácticamente todos los partidos comunistas del continente. $Y$ es que, en efecto, con la desaparición de los fundadores del marxismo latinoamericano - Recabarren (1924), Mella (1929), Mariátegui (1930)—, el movimiento socialista organizado en torno a los partidos comunistas fue cayendo progresivamente en el burocratismo y doctrinarismo dogmático, lo cual fue en detrimento del impulso inicial que apuntaba hacia una "nacionalización del marxismo". Si en el movimiento comunista inicial la tensión doctrina-organización-actividad revolucionaria se había resuelto a favor de la última, siendo la doctrina y la organización aspectos subordinados de la misma, para la segunda generación de comunistas -la que emerge con la institucionalización de los partidos comunistas-, la tensión se resuelve a favor de la organización y la doctrina -que apelaría fuertemente a la discusión sobre las etapas del tránsito

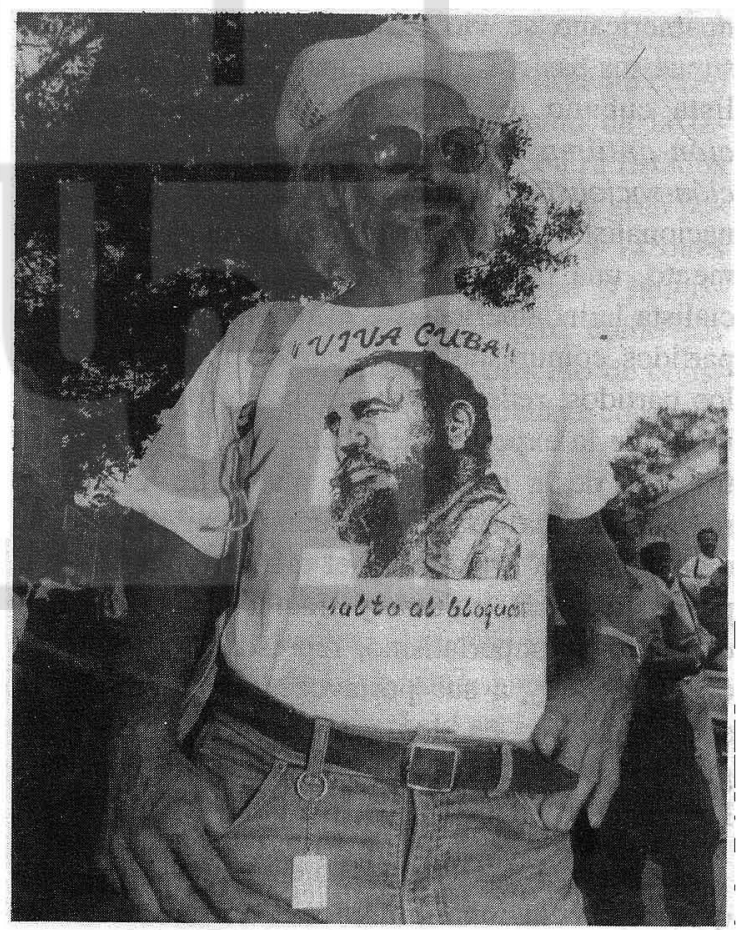


hacia el socialismo-, mientras que la última prácticamente fue sustituida por el reformismo y la lucha por la instauración de las "condiciones democrático-burguesas" entendidas como requisito básico para la conquista del socialismo.

Como resultado de este proceso, la izquierda comunista desligó la construcción de la nación de la actividad revolucionaria. Mientras tanto, el socialismo y el anti-imperialismo se convirtieron en elementos imprescindibles de la retórica revolucionaria de los líderes y secretarios generales de los partidos, pero ajenos a los compromisos prácticos que éstos y sus respectivas organizaciones asumían en cada coyuntura particular. La construcción de la nación — desligada de la voluntad revolucionaria y de los esfuerzos por nacionalizar el marxismo- para los comunistas de la segunda generación se convirtió en un asunto de establecer alianzas estratégicas con la incipiente burguesía nacional con miras a fortalecer el protagonismo de ésta como una clase fundamental para la constitución de un orden burgués, sin el cual pensar en el socialismo no era más que pura ilusión.

No fue sino hasta 1959 , con el triunfo de la revolución cubana, que el "marxismo oficial" latinoamericano se vio sacudido en muchos de sus supuestos básicos. El triunfante movimiento socialista cubano reestableció los vínculos revolución-antiimperialismo-construcción de la nación-socialismo con lo cual actualizó los ideales nacionalistas de José Martí. A partir de este momento, una parte importante del movimiento socialista latinoamericano —el que se desligó de los partidos comunistas tradicionales o el que, desde los partidos, redefinió su compromiso socialista a la luz de la experiencia cubana- asumió la construcción de la nación en el marco de la tensión señalada arriba. Es decir, la construcción de la nación como un proceso en el que, privilegiando la propia realidad, cultura y tradiciones, había que enfrentar al imperialismo, representado por Estados Unidos, y a sus portavoces al interior de la sociedad, esto es, los grupos oligárquicos, los grandes empresarios capitalistas y los agentes de las grandes firmas transnacionales.

Este ideal nacionalista fue el ideal de la izquierda revolucionaria latinoamericana desde me- diados de siglo. Hacia fines del siglo $\mathrm{XX}$, muchas cosas han cambiado en el mundo y en la propia izquierda. Y ello plantea la necesidad de repensar el ideal nacionalista tal y como históricamente terminó por asumirlo el movimiento socialista latinoamericano. Empero, antes de reflexionar en torno a este punto, es necesario dejar constancia de que durante el despliegue del "marxismo institucionalizado" y sus propuestas para construir la nación, otro movimiento sociopolítico latinoamericano se planteó, quizás con mucha mayor eficacia, la construcción de la nación. Se trata del movimiento aprista que, bajo la conducción de Víctor Raúl Haya de la Torre (1895-1979), se propuso - pretendiendo constituirse en una superación del proyecto socialista - la fundación de la nación.

La propuesta de Haya de la Torre para la construcción de la nación es anti-imperialista: el imperialismo ejerce el control de la economía nacional, lo cual hace imposible incluso el desarrollo autónomo de un capitalismo y la superación del feudalismo colonial latinoamericano. Por tanto, se trata de combatir la presencia imperialista y el feudalismo, para lo cual es necesario forjar un frente multiclasista que, independientemente de la adscripción de clase de sus miembros, "se proponga la constitución de un Estado anti-imperialista cuyo núcleo esté formado por los grupos medios que son los más lúcidos y conscientes de dicha dominación" (F. Zapata, Ibid., p. 102).

En cierto modo, los regímenes populistas latinoamericanos vinieron a dar concreción a la propuesta de Haya de la Torre. El fortalecimiento estatal, la industrialización sustitutiva de importaciones y la ampliación de los espacios de participación política popular fueron, entre otros, los rasgos básicos de esos regímenes políticos. Sin embargo, ni se constituyó un frente multiclasista capaz de integrar y armonizar los intereses de la sociedad global en torno a esa meta común - la fundación de una identidad nacional y, consecuentemente, de la nación- ni el imperialismo dejó de hacerse presente en la dinámica socio-económica, ni se alcanzó el desarrollo autónomo esperado.

El advenimiento de los "regímenes burocrático autoritarios" (G. O'Donnel) no sólo mostró las debilidades del proyecto nacional abanderado por los 
populistas, sino que vino a echar por los suelos los incipientes cimientos de la relativa "autonomía" nacional que los regímenes habían logrado, no sin dificultades, afianzar. Y es que si en alguna etapa del desarrollo histórico latinoamericano se puede hablar de la consolidación al menos incipiente de un Estado-nación en algunos de los países del continente, esa etapa fue la que vio consolidarse a los regímenes populistas, que se desplegaron en el marco de lo que algunos teóricos denominan "matriz Estado céntrica" (L. A. González, "Estado, mercado y sociedad civil en América Latina", $E C A, 1994,552$, pp. 1045-1057).

Las dictaduras militares no sólo aplicaron medidas drásticas de carácter represivo para desarticular las estructuras organizativas de la sociedad -parlamentos, partidos y sindicatos-, sino que implementaron, con las variantes particulares en cada caso, medidas de política económica tendientes a "desnacionalizar" la economía, abriendo brecha muchas veces explícitamente a la avanzada neoliberal. Los militares latinoamericanos, so pretexto de restaurar el orden y de superar la crisis económica, arrasaron con las instituciones democráticas vigentes y crearon las condiciones - desde el control del aparato estatal- para la expansión sin límites del mercado.

$Y$, mientras los militares truncaban desde dentro el esfuerzo de construcción de la nación abanderado por los populistas, la economía mundial se reestructuraba y daba paso a un irreversible proceso de globalización, en el cual ni el proyecto nacional socialista ni el proyecto populista encontrarían cabida. En los umbrales del siglo XXI, América Latina -con sus diferencias étnicas, sociales, económicas y políticas- se encuentra inserta en la lógica globalizadora de la economía mundial, que no conoce fronteras ni la distinción entre lo nacional y lo internacional.

La globalización constituye el gran desafío del nacionalismo latinoamericano, especialmente del nacionalismo socialista. Sobre todo porque con la globalización es la construcción de la nación lo que, como en el pasado, está en juego. Porque globalización significa depredación de los recursos naturales, exclusión y marginación socio-económica de la mayor parte de la población del continen- te, avasallamiento de las identidades étnicas y culturales de la región y, en definitiva, atraso y subdesarrollo.

El asunto es si el nacionalismo abanderado por la izquierda latinoamericana a lo largo del siglo $\mathrm{XX}$ constituye una respuesta viable para los desafíos que plantea el fin del milenio. Y, si no es así, surge la interrogante - y la duda - de si la izquierda está preparada para formular un nuevo proyecto nacional. Este es uno de los retos mayores que tiene la izquierda latinoamericana en los umbrales del siglo XXI, la cual —dadas las causas que ha defendido a lo largo del siglo XX y dados los referentes de identidad y los compromisos que la orientan- no puede dejar de ser nacionalista.

Las siguientes reflexiones de Jorge Castañeda plantean en sus justos términos los desafíos del nacionalismo latinoamericano de izquierda al finalizar el milenio:

Ya que en América Latina la construcción nacional sigue siendo inconclusa y la causa del cambio social es inseparable de la tarea de rescatar la "nación" para el pueblo, la izquierda no tiene más opción que seguir siendo nacionalista. La meta de construir naciones a las que puedan pertenecer millones de latinoamericanos excluidos (...) es tan válida y urgente como antes. Buena parte del nacionalismo de la izquierda se dirigió por largo rato contra Estados Unidos, el cual subsiste como la única gran potencia del mundo, y nuevas formas y razones para la ingerencia norteamericana en el hemisferio sustituyen a las viejas. Pero como los parámetros y la definición en proceso de construcción cambian, debe determinarse cómo ha de evolucionar el nacionalismo.

El aggiornamento de la izquierda no puede implicar la abdicación de la agenda nacionalista o el abandono de las tareas de construcción nacional aún pendientes. Hoy más que nunca, la situación social de Latinoamérica se asemeja al tipo de modelo de apartheid social que constituye la antítesis misma de la formación de la nación completa: la brecha entre ricos y pobres, blancos y otros, incluidos y excluidos, es mayor que en cualquier otro momento de los 
últimos veinte años y se está enșanchando. A la vez, las tentaciones procedentes de afuera que recaen sobre las autoridades latinoamericanas para apartarlas de las posiciones nacionalistas del pasado también son más intensas que antes. La necesidad de asegurar un financiamiento que escasea, de parecer responsables y "maduros" y de ajustarse a las modas de globalización postmarxistas y postsocialistas es un apremio muy potente que ha obligado a políticos sensatos de centro y centro-derecha a asumir posiciones antinacionalistas que de otro modo no tomarían. Ambos motivos - las diferencias abismales internas en la sociedad latinoamericana y la "desnacionalización" de las élites- son poderosos incentivos para que la izquierda mantenga un nacionalismo tan poco de moda en estos tiempos, pero tan necesario (J. C. Castañeda, La utopía desarmada. Intrigas, dilemas y promesa de la izquierda en América Latina. México, 1993. pp. 353 y 360.)

Ahora bien, ¿cuál es nacionalismo que debe abanderar la izquierda en los umbrales del siglo XXI? ¿De qué nacionalismo se trata? Es precisamente aquí donde comienzan los problemas, porque "uno de los principales retos a los que ha de hacer frente la izquierda en la actualidad es la elaboración de una nueva propuesta nacionalista... reto [que] sólo se puede satisfacer con el paso del tiempo de un lado al otro del hemisferio" (Castañeda, Ibid., p. 362). Sin embargo y pese a que ese "nuevo nacionalismo" de izquierda no da indicios de haber comenzado a formularse, no puede abandonar el impulso integrador de los excluidos que dinamizó a la tradición nacionalista tal y como ésta fue desarrollada por José Martí, Emilio Recabarren, Julio Antonio Mella, José Carlos
Maríategui o Haya de la Torre. Pero, sin abandonar el mejor legado de esta tradición, el nacionalismo de izquierda de fines de siglo debe insertar la "recuperación de la nación" para los desposeídos en el contexto de los procesos democratizadores desencadenados a partir de los años ochenta en la mayoría de países latinoamericanos.

Dicho lo anterior, podemos concluir con Jorge Castañeda sosteniendo lo siguiente:

En definitiva, el nacionalismo de la izquierda latinoamericana, nuevo o viejo, debe subordinarse a su esperanza y su lucha para "devolver la nación al pueblo", o para ser más precisos, para dar a los millones de ciudadanos excluidos del hemisferio la nación que nunca tuvieron. Este nacionalismo forma parte tanto de la agenda interna como internacional. Significa extender el proceso de democratización que se inició en toda Latinoamérica en los años ochenta mucho más allá de sus límites actuales en cada país. Si no se incorpora la mayoría del pueblo a la nación, el nacionalismo de unos cuantos - la élite intelectual, la clase media urbana profesional, la clase media urbana empobrecida, [los] maestros de escuela, estudiantes y trabajadores itinerantes - nunca logrará una verdadera base electoral. Hoy, el nacionalismo en Latinoamérica debe convertirse una vez más - como lo hizo en los años treinta y cuarenta de un modo deformado y con frecuencia autoritario, pero a pesar de todo inclusivo - en una fuerza para incorporar a los excluidos de la nación. Pero esta vez debe hacerlo democráticamente (lbid., pp. 384-385).

L. A. G. 